\title{
MIF inhibits the formation and toxicity of misfolded SOD1 amyloid aggregates: implications for familial ALS
}

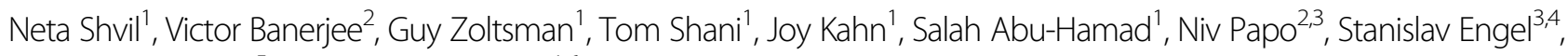
Jurgen Bernhagen ${ }^{5}$ and Adrian Israelson ${ }^{1,6}$

\begin{abstract}
Mutations in superoxide dismutase (SOD1) cause amyotrophic lateral sclerosis (ALS), a fatal neurodegenerative disease caused by the progressive loss of motor neurons in the brain and spinal cord. It has been suggested that toxicity of mutant SOD1 results from its misfolding, however, it is yet unclear why misfolded SOD1 accumulates specifically within motor neurons. We recently demonstrated that macrophage migration inhibitory factor (MIF)-a multifunctional protein with cytokine/chemokine activity and cytosolic chaperone-like properties-inhibits the accumulation of misfolded SOD1. Here, we show that MIF inhibits mutant SOD1 nuclear clearance when overexpressed in motor neuron-like NSC-34 cells. In addition, MIF alters the typical SOD1 amyloid aggregation pathway in vitro, and, instead, promotes the formation of disordered aggregates, as measured by Thioflavin T (ThT) assay and transmission electron microscopy (TEM) imaging. Moreover, we report that MIF reduces the toxicity of misfolded SOD1 by directly interacting with it, and that the chaperone function and protective effect of MIF in neuronal cultures do not require its intrinsic catalytic activities. Importantly, we report that the locked-trimeric MIF ${ }^{\mathrm{N} 110 \mathrm{C}}$ mutant, which exhibits strongly impaired CD74-mediated cytokine functions, has strong chaperone activity, dissociating, for the first time, these two cellular functions. Altogether, our study implicates MIF as a potential therapeutic candidate in the treatment of ALS.
\end{abstract}

\section{Introduction}

Amyotrophic lateral sclerosis (ALS) is a progressive and fatal neurodegenerative disease, which belongs to the family of protein misfolding and protein aggregation diseases, and is characterized by the selective loss of upper and lower motor neurons. Approximately $10 \%$ of all ALS cases are familial, wherein most genes are inherited in an autosomal dominant manner ${ }^{1}$. About $20 \%$ of familial ALS cases are attributed to mutations in the gene encoding the cytoplasmic $\mathrm{Cu} / \mathrm{Zn}$ superoxide dismutase $(\mathrm{SOD} 1)^{2}$, and

\footnotetext{
Correspondence: Adrian Israelson (adriani@bgu.ac.il)

${ }^{1}$ Department of Physiology and Cell Biology, Faculty of Health Sciences, BenGurion University of the Negev, P.O.B. 653, Beer Sheva 84105, Israel

${ }^{2}$ Department of Biotechnology Engineering, Faculty of Engineering, BenGurion University of the Negev, P.O.B. 653, Beer Sheva 84105, Israel

Full list of author information is available at the end of the article

Edited by A. Verkhratsky
}

more than 150 mutations in SOD1 have been identified and described as causing ALS in a dominant manner ${ }^{3,4}$. Several hypotheses have been proposed to explain mutant SOD1-mediated toxicity, but the mechanisms responsible for motor neuron degeneration in ALS have not been fully elucidated. Phenotypically, mutant SOD1 toxicity in ALS is universally attributed to SOD1 misfolding and aggregation $^{5}$, with a clear inverse correlation between mutant SOD1 misfolding and aggregation and disease duration in SOD1 patients ${ }^{6-8}$, suggesting that a gain of novel noxious function upon misfolding may be involved in the pathogenesis of ALS, as proposed previously ${ }^{9}$. In line with this suggestion, is the fact that insoluble aggregates in both familial and sporadic ALS cases are SOD1immunoreactive $\mathrm{e}^{10,11}$. 
Unlike wild-type SOD1 (SOD1 ${ }^{\mathrm{WT}}$ ), mutant SOD1 has been shown to associate with mitochondria ${ }^{12-17}$ and/or the endoplasmic reticulum (ER) ${ }^{18-21}$ solely in tissues from the nervous system. Specifically, the association of mutant SOD1 with the ER has been implicated in ER stress induction $^{18-21}$, and misfolded SOD1 association with mitochondria has been shown to directly bind the voltagedependent anion channel-1 (VDAC1) and to inhibit its conductance of adenine nucleotides across the outer mitochondrial membrane ${ }^{13}$. This inhibition was found to be specific to spinal cord mitochondria and has not been observed in mitochondria extracted from unaffected tissues $^{13,22}$. In addition, mutant SOD1 was shown to interact with, and alter the function of other components of the mitochondrial outer membrane, including $\mathrm{Bcl}-2^{23}$ and the protein import machinery ${ }^{22}$. Despite their potential to shed light on mutant SOD1-induced toxicity in ALS, the molecular factors that determine the cell specificity of misfolded SOD1 proteins, and which drive them to bind and accumulate solely within intracellular membranes of the nervous system, have not yet been identified.

Recently, macrophage migration inhibitory factor (MIF) -a multifunctional protein with cytokine/chemokine activity and cytosolic chaperone-like properties-was shown to inhibit mutant SOD1 misfolding on mitochondria and ER in vitro ${ }^{24}$ and in vivo ${ }^{25}$. At the same time, MIF levels were found to be extremely low within motor neurons ${ }^{24,25}$. In the current study, we used recombinant MIF and SOD1 mutants in a variety of in vitro and cell-based assays to determine the mode of action of MIF as a chaperone for misfolded SOD1. We report that MIF mutants that lack the intrinsic, evolutionarily conserved, tautomerase or oxidoreductase enzymatic activity are able to function as chaperones for misfolded SOD1 and to inhibit mutant SOD1-dependent neuronal cell death. Moreover, we show that the protective effects of MIF are associated with its trimeric conformation, and that MIF directly interacts with SOD1 and suppresses the formation of misfolded SOD1 amyloid aggregates by promoting the conversion of misfolded SOD1 into amorphous disordered aggregates.

\section{Results}

MIF inhibits mutant SOD1 nuclear export in NSC-34 cells

As previously shown, SOD1 is normally localized in both the cytoplasm and the nucleus of cells ${ }^{26,27}$. Recently, Zhong and colleagues showed that the misfolding of SOD1 exposes a nuclear export signal (NES)-like sequence, which is normally buried in correctly folded

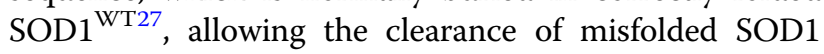
from the nucleus by the nuclear export carrier protein CRM1. In accordance with these findings, we found that when SOD $1^{\text {WT }}$-EGFP and mutant SOD $1^{\text {G93A-EGFP are }}$ expressed in motor neuron-like NSC-34 cells, SOD1 ${ }^{\mathrm{WT}}$ is evenly distributed between the cytoplasm and the nucleus while mutant SOD1 ${ }^{\mathrm{G} 93 \mathrm{~A}}$ shows predominantly cytoplasmic distribution (Fig. 1a, b). Expression of MIF in cells expressing SOD1 ${ }^{\mathrm{WT}}$ had no effect on the distribution of the SOD1 ${ }^{\mathrm{WT}}$-EGFP protein. However, expression of MIF together with the mutant SOD1 $1^{\mathrm{G} 93 \mathrm{~A}}$-EGFP, inhibited the nuclear clearance of misfolded SOD1 resulting in a more wild-type-like distribution of the mutant SOD1 protein (Fig. 1a, b).

Recombinant MIF specifically suppresses the formation of mutant SOD1 amyloid fibrils and induces the formation of disordered amorphous aggregates

We have previously shown that MIF can inhibit the accumulation of misfolded SOD1 in vitro and in vivo ${ }^{24,25}$. To test whether recombinant MIF can prevent the amyloid fibril formation of mutant SOD1, we expressed and purified MIF as described previously ${ }^{28}$ and measured its overall structural integrity and activity by using the hydroxyl-phenolpyruvate (HPP) tautomerase activity assay (Fig. S1). Incubating SOD1 $1^{\mathrm{G} 93 \mathrm{~A}}$ or SOD1 $1^{\mathrm{G} 85 \mathrm{R}}$, another well-established misfolded SOD1 mutant, in the absence of recombinant MIF resulted in an exponential increase in thioflavin $\mathrm{T}$ (ThT) fluorescence (which correlates with amyloid aggregate formation) after a lag time of 30 or $15 \mathrm{~h}$, respectively (Fig. $2 \mathrm{a}, \mathrm{b}$ ). In contrast, incubating mutant SOD $1^{\text {G93A }}$ (Fig. 2a) or SOD ${ }^{\text {G85R }}$ (Fig. 2b) in the presence of recombinant MIF strongly suppressed this increase in a dose-dependent manner. This effect was specific to amyloid aggregates of SOD1, as it was not observed when incubating the amyloid beta peptide $\mathrm{A} \beta_{1-42}$ with increasing MIF concentrations (Fig. 2c).

To determine whether the presence of MIF reduces the total amount of SOD1 aggregates, we conducted a turbidity assay, in which all different forms of aggregates can be measured. Importantly, incubating the mutant SOD1 with MIF did not reduce the total amount of SOD1 aggregation (Fig. 2d) whatsoever, suggesting that MIF can induce misfolded SOD1 to aggregate into a species other than amyloid aggregates. Supporting this notion, transmission electron microscopy (TEM) imaging performed after incubating the SOD1 mutants with or without MIF revealed that, whereas mutant $\mathrm{SOD} 1^{\mathrm{G} 93 \mathrm{~A}}$ and $\mathrm{SOD} 1^{\mathrm{G} 85 \mathrm{R}}$ form fibrous aggregates when incubated alone (Fig. 3a, b), incubating them with recombinant MIF switches the aggregation pattern to an amorphous disordered one (Fig. 3c, d). Incubating MIF alone produced very small aggregates, which were undetectable in the turbidity assay (Fig. 2d) or ThT analysis (Fig. S2).

The conserved catalytic activities of MIF and its oligomeric transition are not required for suppressing the misfolding and toxicity of mutant SOD1 in NSC-34 cells

MIF exhibits evolutionarily conserved catalytic tautomerase $^{29}$ and thiol-oxidoreductase $\mathrm{e}^{30}$ activities, but the 

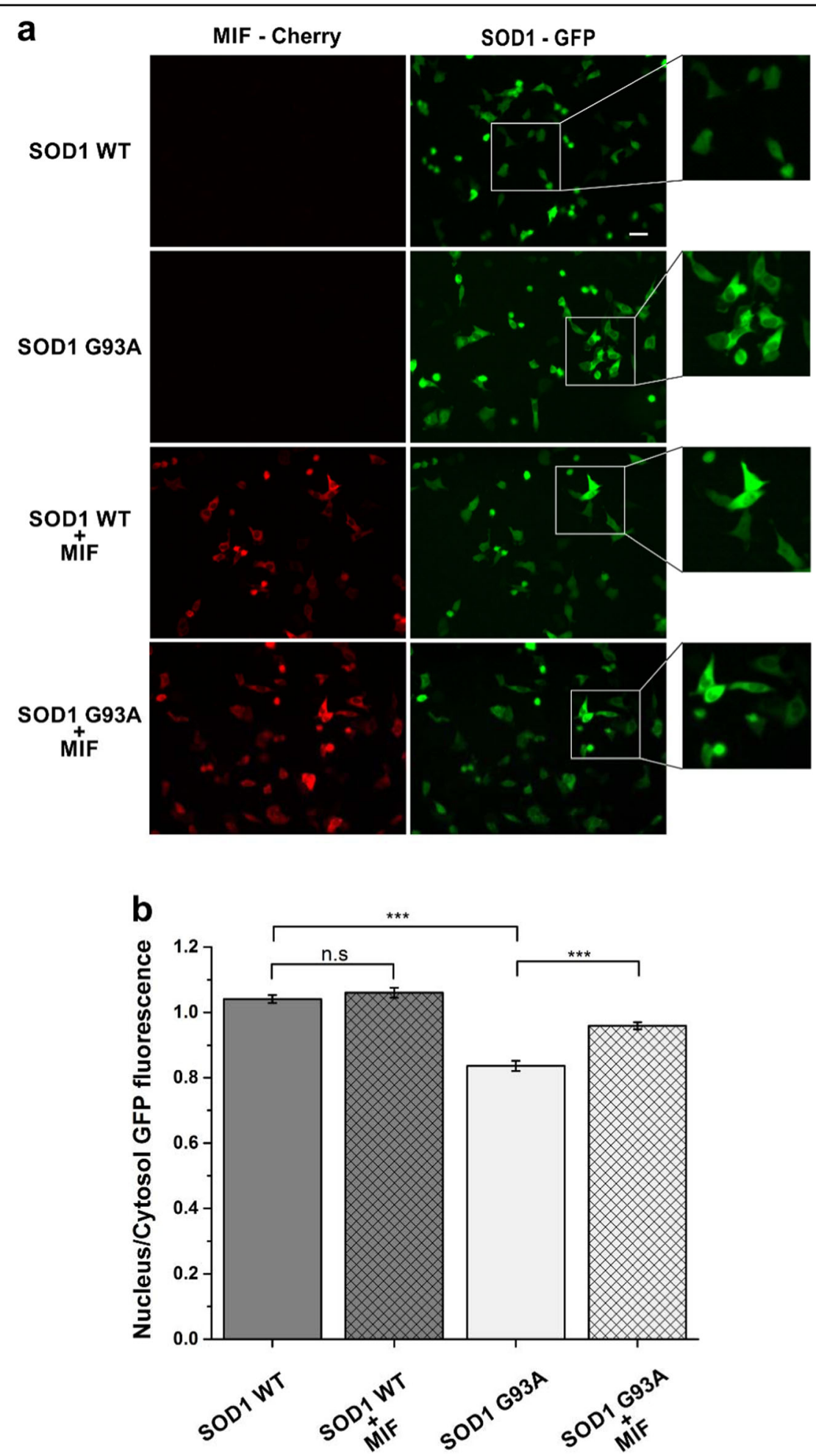

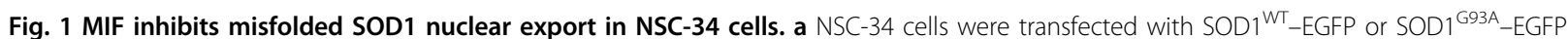
plasmid with or without co-transfection of MIF-Cherry. $24 \mathrm{~h}$ after transfection, between 57-60 images were recorded for each group. Scale bar, $25 \mu \mathrm{m}$. b GFP fluorescence levels in the nucleus and in the cytoplasm were quantified separately by NIS elements (NIKON) program and the ratio for each cell were taken for analysis. One-way ANOVA test was applied on the average of the different groups, all normal distributed, followed by Tukey post hoc test. ${ }^{* *} p<0.001$ 

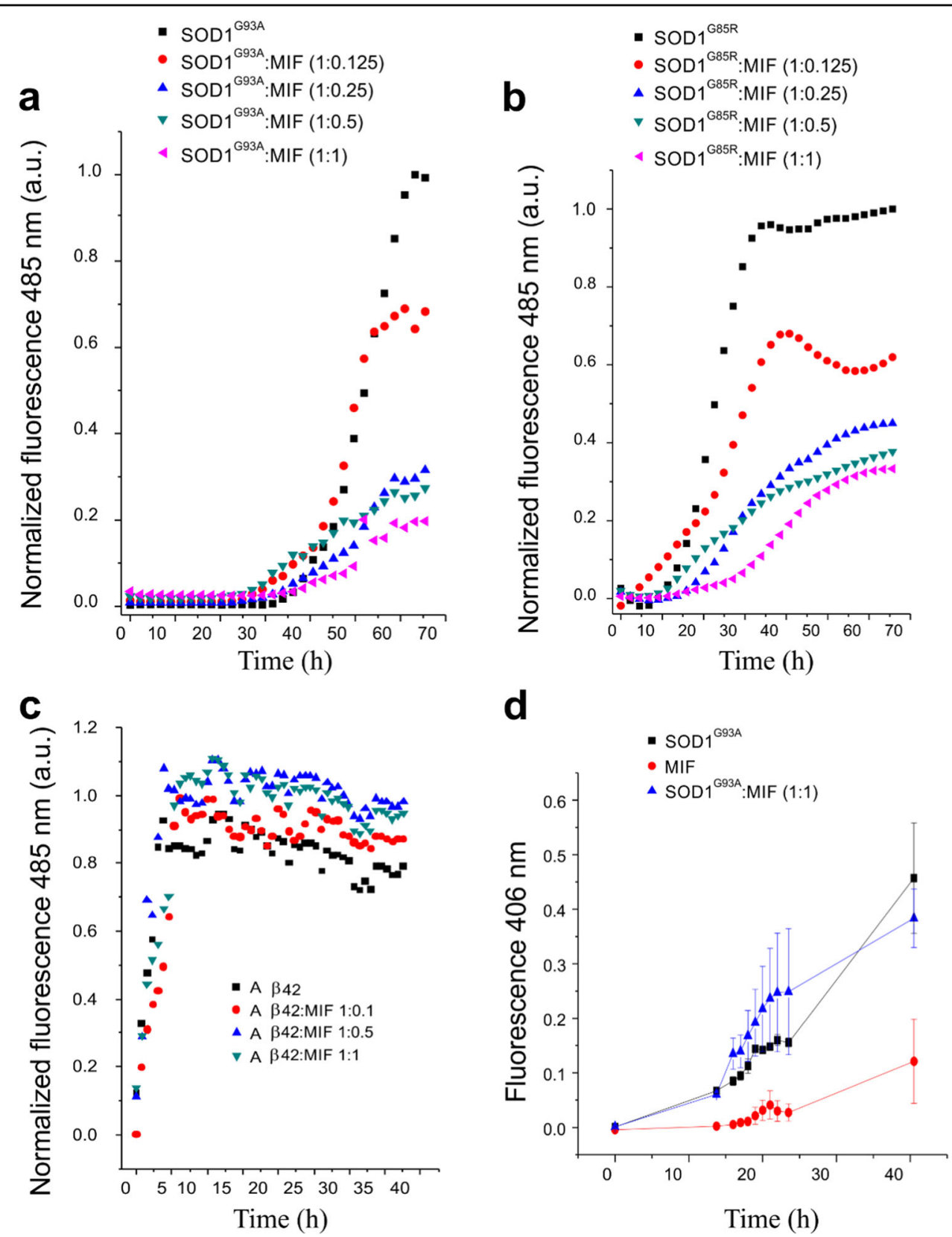

Fig. 2 Recombinant MIF specifically suppresses mutant SOD1 amyloid fibril formation in a dose-dependent manner. ThT fluorescence was monitored during the co-incubation of SOD $1^{\mathrm{G} 93 \mathrm{~A}}(50 \mu \mathrm{M})(\mathbf{a})$ or SOD1 $1^{\mathrm{G} 85 \mathrm{R}}(50 \mu \mathrm{M})(\mathbf{b})$ with recombinant MIF at different molar ratios at $37^{\circ} \mathrm{C}$ with continuous shaking. The values were normalized to the maximal ThT intensity elicited by SOD $1^{\mathrm{G} 93 \mathrm{~A}}$ or SOD1 ${ }^{\mathrm{G} 85 \mathrm{R}}$ alone. $\mathbf{c}$ ThT fluorescence of the $\beta$ amyloid peptide (Ab42) (1.0 $\mu \mathrm{M}$ ), incubated alone or with increasing concentrations of recombinant MIF, under the same conditions as in (a) and (b). Data points in $\mathbf{a}-\mathbf{c}$ represent the average results from one representative experiment (performed in triplicates) of three independent experiments. d An increase in the turbidity measured at $406 \mathrm{~nm}$ indicates the formation of SOD $1^{\mathrm{G} 93 \mathrm{~A}}$ aggregates in solution during shake-incubation at $37^{\circ} \mathrm{C}$, in the absence (black) or presence (blue) of $10 \mu \mathrm{M}$ MIF. The turbidity of MIF alone (10 $\mu \mathrm{M}$; red) is also shown as a control. Of note, in this MIF concentration range (blue symbols) significant inhibition of ThT fluorescence elicited by SOD $1^{\mathrm{G} 93 \mathrm{~A}}$ or SOD $1^{\mathrm{G} 85 \mathrm{R}}$ is seen.

physiologic substrates of these activities have remained elusive. To determine whether the ability of MIF to suppress the accumulation of misfolded SOD1 and protect against mutant SOD1 toxicity depends on these activities, we co-transfected NSC-34 cells with a human wild-type $\left(\mathrm{SOD} 1^{\mathrm{WT}}\right)$ or mutant $\left(\mathrm{SOD} 1^{\mathrm{G} 93 \mathrm{~A}}\right)$ SOD1 transgene together with either wild-type or point-mutated variants of MIF that completely lack tautomerase $\left(\mathrm{MIF}^{\mathrm{P} 2 \mathrm{~A}}\right)$ or 


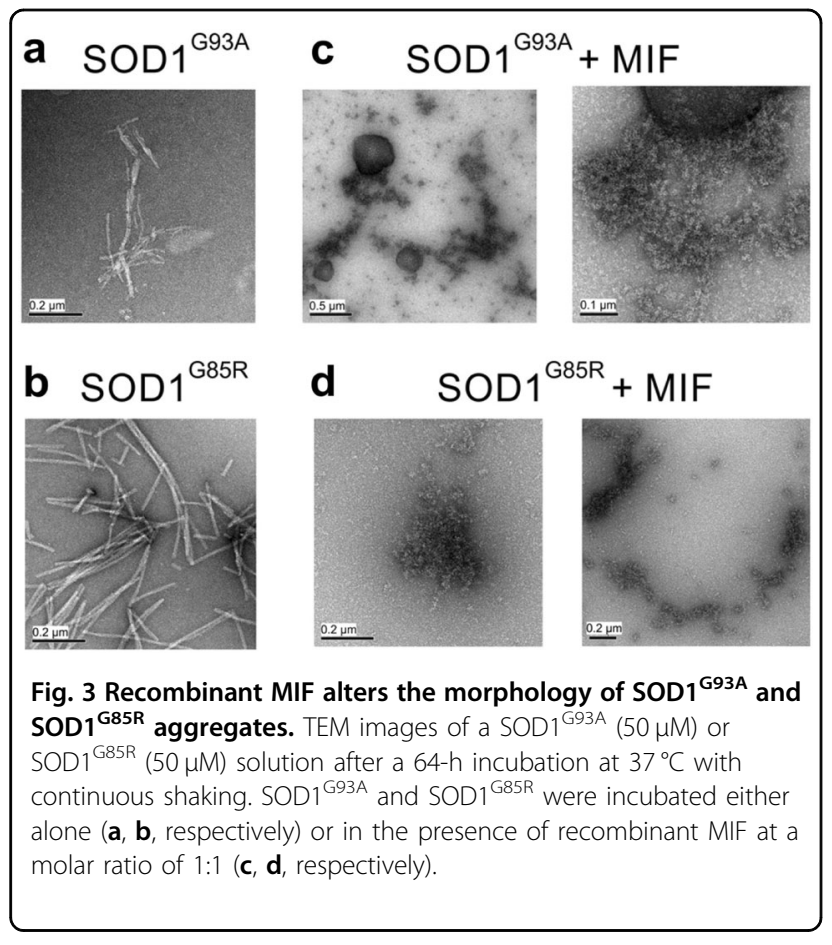

oxidoreductase $\left(\mathrm{MIF}^{\mathrm{C} 60 \mathrm{~S}}\right)$ activities ${ }^{29,30}$. In addition, we transfected cells with a cysteine mutant of MIF $\left(\mathrm{MIF}^{\mathrm{N} 110 \mathrm{C}}\right)$, which covalently locks MIF into a trimeric conformation by forming a disulfide bridge with Cys-81 of an adjacent subunit ${ }^{31}$, thus preventing equilibria between MIF trimers, dimers, and monomers ${ }^{31-33}$ (Fig. 4a).

In the absence of transfected MIF, misfolded SOD1 accumulated and could be detected by immunoprecipitation with the $\mathrm{B} 8 \mathrm{H} 10$ antibody, which recognizes a wide range of misfolded SOD1 mutants, including $\mathrm{SOD} 1{ }^{\mathrm{G} 93 \mathrm{~A}}$ (Fig. 4b). By contrast, expressing SOD1 ${ }^{\mathrm{G} 93 \mathrm{~A}}$ simultaneously with $\mathrm{MIF}^{\mathrm{WT}}$ or with any of the three MIF mutants reduced (although to a lesser extent in the case of $\mathrm{MIF}^{\mathrm{C} 60 \mathrm{~S}}$ ) the levels of misfolded SOD1 (Fig. 4b), but did not affect the overall level of SOD1 expression. In addition, while expressing SOD $1{ }^{\mathrm{WT}}$ did not affect cell survival, expressing mutant SOD1 ${ }^{\mathrm{G} 93 \mathrm{~A}}$ reduced cell survival by approximately $25 \%$. This toxic effect was reversed by coexpressing MIF ${ }^{\mathrm{WT}}$ or any of the three MIF mutants (again with a smaller effect in $\mathrm{MIF}^{\mathrm{C} 60 \mathrm{~S}}$ ) in these cells (Fig. 4c), suggesting that the tautomerase activity of MIF, its thioloxidoreductase activity, or the respective residues, as well as its oligomeric transition states are not required for its chaperone activity and cytoprotective effects. To further support this notion, we performed crosslinking experiments using glutaraldehyde as described previously ${ }^{32}$. Crosslinked MIF ${ }^{\mathrm{WT}}, \mathrm{MIF}^{\mathrm{P} 2 \mathrm{~A}}$ and $\mathrm{MIF}^{\mathrm{C} 60 \mathrm{~S}}$ were found as a mixture of monomeric, dimeric, and trimeric forms, whereas mostly monomeric $\mathrm{MIF}^{\mathrm{WT}}$ was detected when MIF was electrophoresed without prior crosslinking
(Fig. 4d). In contrast to $\mathrm{MIF}^{\mathrm{WT}}$, $\mathrm{MIF}^{\mathrm{P} 2 \mathrm{~A}}$ and $\mathrm{MIF}^{\mathrm{C} 60 \mathrm{~S}}$, the mutant $\mathrm{MIF}^{\mathrm{N} 110 \mathrm{C}}$ was found mostly as a trimeric form when electrophoresed without prior crosslinking, as expected $^{31}$ (Fig. 4d).

\section{The locked-trimeric mutant $\mathrm{MIF}^{\mathrm{N} 110 \mathrm{C}}$ strongly suppresses the formation of mutant SOD1 amyloid fibrils}

We next tested whether the formation of mutant SOD1 amyloid fibrils can be prevented by co-incubation with $\mathrm{MIF}^{\mathrm{WT}}, \mathrm{MIF}^{\mathrm{C} 60 \mathrm{~S}}, \mathrm{MIF}^{\mathrm{P} 2 \mathrm{~A}}$, or $\mathrm{MIF}^{\mathrm{N} 110 \mathrm{C}}$, all of which had a protective effect in the NSC-34 cells. To this end, we incubated the human SOD $1^{\mathrm{G} 93 \mathrm{~A}}$ apo-protein in the absence or presence of recombinant $\mathrm{MIF}^{\mathrm{WT}}$, or its mutants (Fig. 4d) and measured ThT fluorescence over time. In order to confirm that all the proteins that we used were soluble at the concentration used, we performed a turbidity assay to measure protein aggregate formation. At $50 \mu \mathrm{M}$ of recombinant MIF, we observed that MIF ${ }^{\mathrm{WT}}$, $\mathrm{MIF}^{\mathrm{C} 60 \mathrm{~S}}, \mathrm{MIF}^{\mathrm{P} 2 \mathrm{~A}}$, and $\mathrm{MIF}^{\mathrm{N} 110 \mathrm{C}}$ formed insoluble aggregates to some extent when incubated at $37^{\circ} \mathrm{C}$ (about 80 , 50,75 , and $60 \%$ of the protein remained in the soluble fraction, respectively) (Fig. S3a and b), therefore we reduced the working concentration of MIF to $10 \mu \mathrm{M}$. At this concentration, no insoluble aggregates were formed (Fig. S3c, Fig. 2d). In the absence of MIF, the typical exponential rise in ThT fluorescence was observed after the typical lag time. This increase was strongly suppressed when the SOD1 ${ }^{\mathrm{G} 93 \mathrm{~A}}$ mutant was incubated in the presence of recombinant $\mathrm{MIF}^{\mathrm{WT}}$, MIF ${ }^{\mathrm{C} 60 \mathrm{~S}}$, or $\mathrm{MIF}^{\mathrm{P} 2 \mathrm{~A}}$ (Fig. 5a, b). Of note, the locked-trimeric mutant MIF ${ }^{\mathrm{N} 110 \mathrm{C}}$ prevented the rise in ThT fluorescence, suggesting a strong inhibition in the formation of SOD1 amyloid aggregates (Fig. 5b). This finding was validated by TEM images (Fig. 5c). Similar to the addition of MIF ${ }^{\mathrm{WT}}$, addition of MIF ${ }^{\mathrm{N} 110 \mathrm{C}}$ completely changed the pattern of SOD1 aggregates to amorphous aggregates. In contrast, after addition of $\mathrm{MIF}^{\mathrm{C} 60 \mathrm{~S}}$ or $\mathrm{MIF}^{\mathrm{P} 2 \mathrm{~A}}$, a mix of amyloid fibrils and amorphous aggregates could be visualized (Fig. 5c). Furthermore, misfolded SOD1 immunoprecipitation using an $\mathrm{A} 5 \mathrm{C} 3$ antibody was inhibited in the presence of recombinant $\mathrm{MIF}^{\mathrm{WT}}$ or of any of the three MIF mutants (Fig. 6). Surprisingly, in contrast to $\mathrm{MIF}^{\mathrm{WT}}$, which does not co-precipitate with misfolded SOD1, the locked trimeric mutant $\mathrm{MIF}^{\mathrm{N} 110 \mathrm{C}}$ strongly co-precipitated with misfolded SOD1 (Fig. 6), suggesting a higher affinity of SOD1 to the locked trimeric form of MIF.

\section{MIF $^{\mathrm{N} 110 \mathrm{C}}$ directly interacts with apo-SOD1 with higher affinity than MIF ${ }^{\mathrm{WT}}$ as determined by real time surface plasmon resonance (SPR)}

Recombinant MIF ${ }^{\mathrm{WT}}$ and $\mathrm{MIF}^{\mathrm{N} 110 \mathrm{C}}$ were purified and their interactions with recombinant SOD1 demonstrated using SPR technology (Fig. 7). Poly-histidine tagged apoSOD1 or HTB1 (as negative control) were immobilized on 

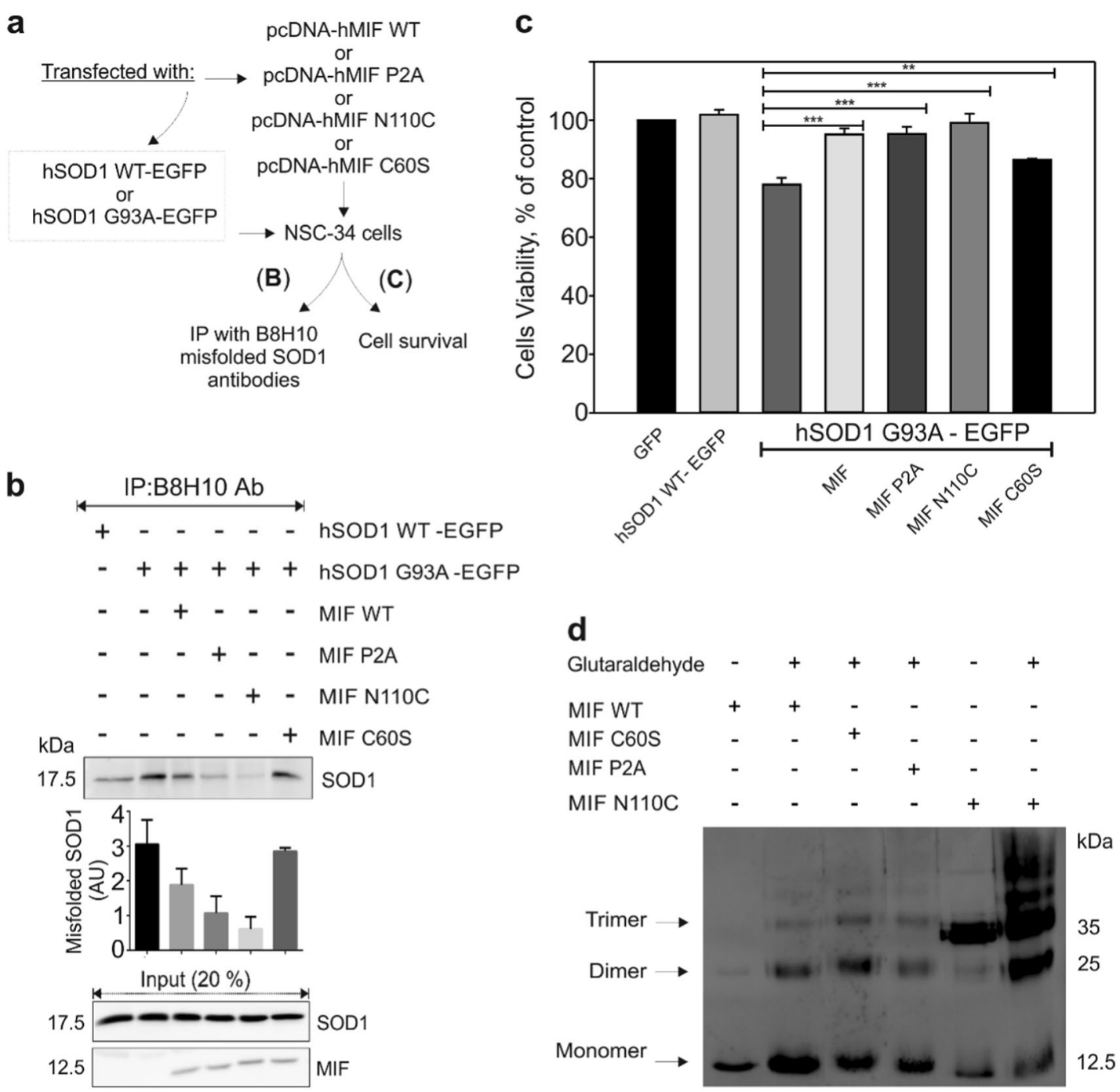

Fig. 4 The catalytic activities of MIF and its oligomeric transition are not decisive for its chaperone activity and its protective effect against mutant SOD1 toxicity in NSC-34 cells. a A schematic representation of the experimental protocol. MIF-dependent inhibition of misfolded SOD1 accumulation and toxicity was tested in motor neuron-like NSC-34 cells, which were transfected to express the human wild-type SOD1 $\left(\mathrm{SOD} 1^{\mathrm{WT}}\right.$-GFP) or the human mutant SOD1 ${ }^{\mathrm{G} 93 \mathrm{~A}}$-GFP with wild-type MIF (MIF ${ }^{\mathrm{WT}}$ ), MIF ${ }^{\mathrm{C} 60 \mathrm{~S}}, \mathrm{MIF}^{\mathrm{P} 2 \mathrm{~A}}$, or MIF ${ }^{\mathrm{N} 110 \mathrm{C}}$. The cells were then subjected to an immunoprecipitation assay (b) or to a cell-survival assay (c). b Misfolded SOD1 was detected by immunoblotting of immunoprecipitates produced with the B8H10 antibody, which recognizes misfolded SOD1. EGFP-tagged wild-type or mutant human SOD1 levels were determined by immunoblotting in the initial cytosolic fractions. The presence and absence of MIF are represented by plus and minus signs, respectively. This immunoblot is representative of three different independent experiments. c A cell-survival analysis was performed with the CellTiter 96 AQueous onesolution cell proliferation assay with ELISA at $490 \mathrm{~nm}$. Quantitative analysis from triplicates of different biological experiments was performed with a Student's t-test $(n=3) ;{ }^{* *} p<0.01,{ }^{* * *} p<0.001$. d SDS-PAGE and immunoblot of recombinant MIF ${ }^{\mathrm{WT}}, \mathrm{MIF}^{\mathrm{C} 60 \mathrm{~S}}, \mathrm{MIF}^{\mathrm{P} 2 \mathrm{~A}}$, and MIF ${ }^{\mathrm{N} 110 \mathrm{C}}$ after crosslinking with glutaraldehyde. Recombinant MIF ${ }^{\mathrm{WT}}$ and mutant proteins at a concentration of $10 \mu \mathrm{M}$ were crosslinked with $1 \%$ glutaraldehyde and samples electrophoresed as indicated. Wild-type MIF and non-crosslinked samples were analyzed for comparison. The monomer, dimer and trimer oligomers are indicated. +, sample crosslinked prior to electrophoresis; -, non-crosslinked control. This is one representative experiment out of three independent experiments performed.

the surface of the SPR biosensor chip. Increasing concentrations $(31-1000 \mathrm{nM})$ of $\mathrm{MIF}^{\mathrm{WT}}$ or $\mathrm{MIF}^{\mathrm{N} 110 \mathrm{C}}$ were injected onto the sensor chips and binding to apo-SOD1 or HTB1 was monitored. Both $\mathrm{MIF}^{\mathrm{WT}}$ and $\mathrm{MIF}^{\mathrm{N} 110 \mathrm{C}}$ strongly bound to immobilized apo-SOD1 in a concentration- and time-dependent manner (Fig. 7a, b). However, MIF ${ }^{\mathrm{N} 110 \mathrm{C}}$ showed a slower dissociation from the immobilized apo-SOD1 protein. The apparent binding affinities of MIF ${ }^{\mathrm{WT}}$ and $\mathrm{MIF}^{\mathrm{N} 110 \mathrm{C}}$ to apo-SOD1 were derived from the sensogram of the steady-state values and 


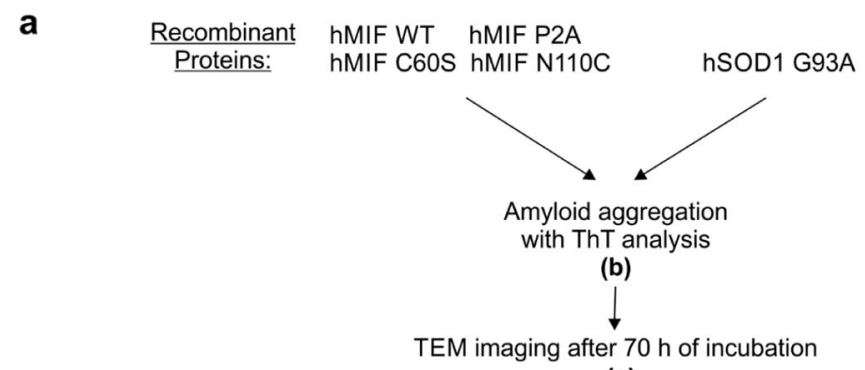

(c)
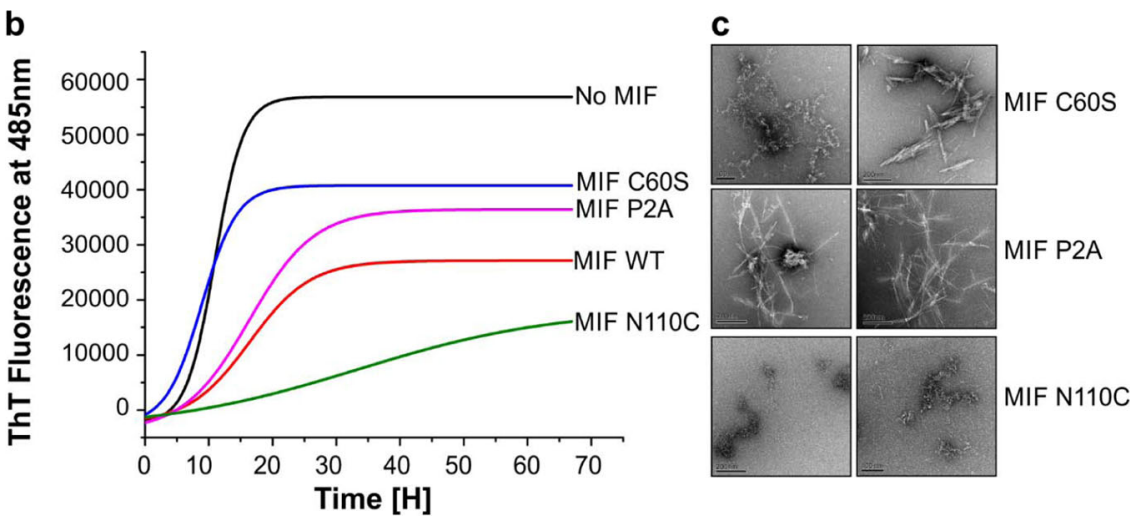

Fig. 5 The locked-trimeric mutant $\mathrm{MIF}^{\mathrm{N} 110 \mathrm{C}}$ completely suppresses amyloid fibril formation of the mutant SOD1. a Experimental protocol used for determining whether purified recombinant MIF ${ }^{\mathrm{WT}}$ or MIF mutants suppress the amyloid aggregation of misfolded SOD1, as detected by ThT and TEM . b ThT fluorescence was monitored during the incubation $\left(37^{\circ} \mathrm{C}\right.$ with continuous shaking) of mutant $\operatorname{SOD}{ }^{\mathrm{G}}{ }^{93 \mathrm{~A}}(50 \mu \mathrm{M})$, either without (black) or with recombinant MIF ${ }^{W T}$ (red), $\mathrm{MIF}^{\mathrm{C} 60 \mathrm{~S}}$ (blue), $\mathrm{MIF}^{\mathrm{P} 2 \mathrm{~A}}$ (pink), or $\mathrm{MIF}^{\mathrm{N} 110 \mathrm{C}}$ (green), all at a $10 \mu \mathrm{M}$ concentration. Fluorescence was normalized to the maximal ThT fluorescence intensity that was elicited by SOD ${ }^{\mathrm{G} 93 \mathrm{~A}}$ alone. Data indicate the average of $30-50$ replicates performed from three independent experiments. Fluorescence was fitted to Boltzmann sigmoidal equation using OriginPro 8.5 software. c TEM images of a SOD ${ }^{\text {G93A }}$ (50 $\mu \mathrm{M}$ ) solution after a 68 -h incubation at $37^{\circ} \mathrm{C}$ with continuous shaking. SOD $1^{\mathrm{G} 93 \mathrm{~A}}$ was incubated in the presence of recombinant MIF ${ }^{\mathrm{C} 60 \mathrm{~S}}$, MIF ${ }^{\mathrm{P} A}$, or $\mathrm{MIF}^{\mathrm{N} 110 \mathrm{C}}$ at a molar ratio of 5:1.

calculated to be $1.3 \pm 0.27 \mu \mathrm{M}$, and $0.548 \pm 0.18 \mu \mathrm{M}$ for $\mathrm{MIF}^{\mathrm{WT}}$ and $\mathrm{MIF}^{\mathrm{N} 110 \mathrm{C}}$, respectively. The results thus demonstrate direct and specific interaction of $\mathrm{MIF}^{\mathrm{WT}}$ and $\mathrm{MIF}^{\mathrm{N} 110 \mathrm{C}}$ with apo-SOD1, with a higher affinity for $\mathrm{MIF}^{\mathrm{N} 110 \mathrm{C}}$.

\section{Discussion}

One of the most critical standing questions in the field of neurodegenerative diseases is the enigma of what determines the selective death of specific neuronal populations. In ALS cases related to mutant SOD1, the second most common form of familial ALS, the degeneration of motor neurons is accompanied by the specific misfolding of mutant SOD1. Several groups have reported the accumulation of misfolded SOD1 also in sporadic cases of ALS ${ }^{10,34-40}$, although other groups came to the opposite conclusion $^{41-46}$. Misfolded SOD1 associates with mitochondria and ER membranes, and aggregates only in affected tissues. Recently, we demonstrated that the association of mutant SOD1 with intracellular membranes can be inhibited by the cytosolic multifunctional mediator $\mathrm{MIF}^{47}$, which significantly suppresses the accumulation of misfolded $\mathrm{SOD}^{24}$. Moreover, we showed that MIF levels are low within motor neurons, as compared with other cell types, and that increasing MIF levels in mutant SOD1 expressing motor neurons can extend their survival ${ }^{24}$. Finally, we showed, in vivo, that reducing the chaperone activity of MIF plays a pivotal role in the accumulation of misfolded SOD1 and in its consequential toxicity ${ }^{25}$. By breeding MIF-null mice with mutant SOD1 ${ }^{\mathrm{G} 85 \mathrm{R}}$ mice, we showed that mutant SOD1 mice that lack MIF expression have an accelerated disease onset and progression, and a shorter survival time than their mutant SOD1 littermates. This effect was accompanied by an increase in the accumulation of misfolded SOD1 and its association with mitochondria and ER membranes, apparent even in early stages and before the appearance of symptoms ${ }^{25}$.

In the current study, we deal with one of the most important unresolved questions; how does MIF protect 


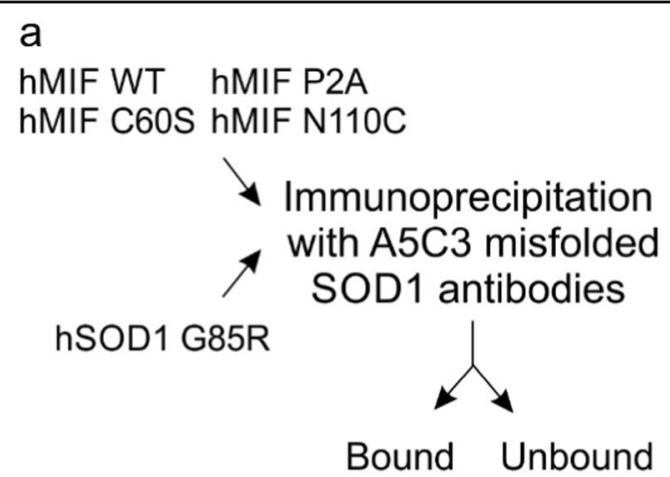

(b)

b
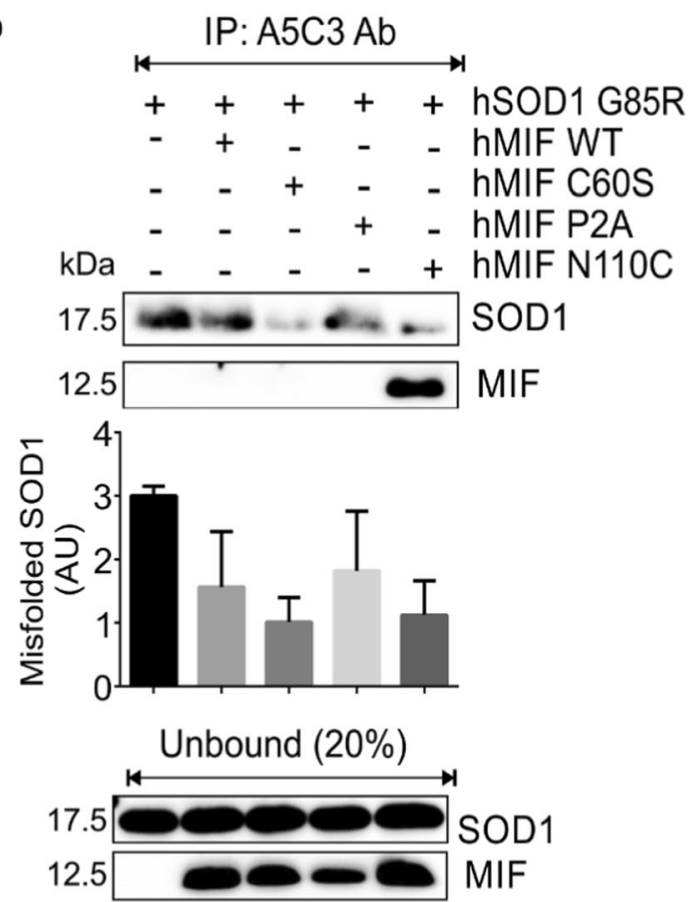

Fig. 6 MIF inhibition of mutant SOD1 misfolding is independent of its enzymatic activities or its normal oligomeric transitions. a Schematic diagram of the experiment. $\mathbf{b}$ The accumulation of misfolded SOD1 was determined by immunoblotting of immunoprecipitates with the $\mathrm{A} 5 \mathrm{C} 3$ antibody after incubating recombinant $\mathrm{hSOD} 1^{\mathrm{G} 85 \mathrm{R}}(4 \mu \mathrm{g})$ with (+) or without (-) recombinant $\mathrm{MIF}^{\mathrm{WT}}$, MIF ${ }^{\mathrm{C} 60 \mathrm{~S}}, \mathrm{MIF}^{\mathrm{P} 2 \mathrm{~A}}$, or $\mathrm{MIF}^{\mathrm{N} 110 \mathrm{C}}$ (all at $2 \mu \mathrm{g})$. Immunoblotting was used to determine the levels of SOD1 and MIF that remained in the unbound fraction of each immunoprecipitation assay. This immunoblot is representative of three independent experiments.

motor neurons from toxic misfolded SOD1 accumulation? Specifically, we demonstrate that MIF suppresses the toxicity of misfolded SOD1 in motor neuron-like cells by directly interacting with misfolded SOD1 and by changing the aggregation pattern from amyloid aggregates to amorphous ones. In addition, we show that MIF inhibits the export of mutant SOD1 from the nucleus to the cytoplasm in these neuronal cells.
MIF was one of the first cytokines to be described ${ }^{48}$. Intracellularly, MIF was previously shown to act as a chaperone $\operatorname{protein}^{49}$ and as a thiol-protein oxidoreductase $^{30}$, in addition to possessing a tautomerase activity-which is observed only in vitro and whose physiological relevance is unclear $^{29}$. Here we show that these catalytic activities are not required for the protective chaperone effect of MIF.

Although the crystal structure of MIF indicates that it is a homo-trimer, MIF monomers and dimers have also been identified ${ }^{32,33,50-53}$. To determine which oligomeric form is necessary for its chaperone activity, we used $\mathrm{MIF}^{\mathrm{N} 110 \mathrm{C}}$ - a previously reported cysteine mutant of MIF, which covalently locks MIF into its trimeric state ${ }^{31,33}$. Notably, while $\mathrm{MIF}^{\mathrm{N} 110 \mathrm{C}}$ retains partial catalytic activity and receptor binding to CD74, it loses its CD74dependent cellular signaling ability as a cytokine ${ }^{31}$. Surprisingly, in our study, MIF $^{\mathrm{N} 110 \mathrm{C}}$, which exists mostly in a trimeric form as was previously shown ${ }^{33}$, in contrast to $\mathrm{MIF}^{\mathrm{WT}}$, not only retained its protective function, but it also showed a strong inhibition of SOD1 amyloid aggregate formation which was more pronounced than that of $\mathrm{MIF}^{\mathrm{WT}}$. Furthermore, while MIF ${ }^{\mathrm{WT}}$, which consists of mixtures of trimeric, dimeric and monomeric species, does not coprecipitate with misfolded SOD1 and shows lower affinity for apo-SOD1 in SPR analysis, the lockedtrimeric mutant has a higher affinity for misfolded SOD1, as can be observed by SPR analysis or by immunoprecipitation using specific conformation antibodies for misfolded SOD1. This can be explained by the increased stability of the MIF trimer compared to the monomer species $^{33}$. Thus, this mutant via its stable conformation, may have a beneficial effect intracellularly such as in the case of misfolded SOD1 binding. On the other hand, Fan and colleagues showed that the locked-trimeric mutant functions as an antagonist for MIF by binding to the MIF receptor CD74 without activating it, probably due to the absence of full flexibility of the locked trimeric mutant ${ }^{31}$. Altogether, these findings suggest that the trimeric form is the preferred one for the MIF chaperone-like activity. Moreover, MIF chaperone activity can be dissociated for the first time from its cellular signaling role as a proinflammatory cytokine.

It is well established that wild-type and mutant SOD1 may aggregate into amyloid fibrils under certain conditions ${ }^{54-60}$. Several studies have demonstrated the general toxicity of amyloid aggregates ${ }^{61-64}$. We show that MIF decreased the amyloid aggregation of SOD $1^{\text {G93A }}$ and SOD $1^{\mathrm{G} 85 \mathrm{R}}$ in a dose-dependent manner, and that its presence changed the aggregation pattern from fibril-like aggregates to amorphous disordered aggregates. This MIF-mediated change in the aggregation pathway of misfolded SOD1 is an important piece of the puzzle, since it was shown that the fibril-like amyloid aggregates of 

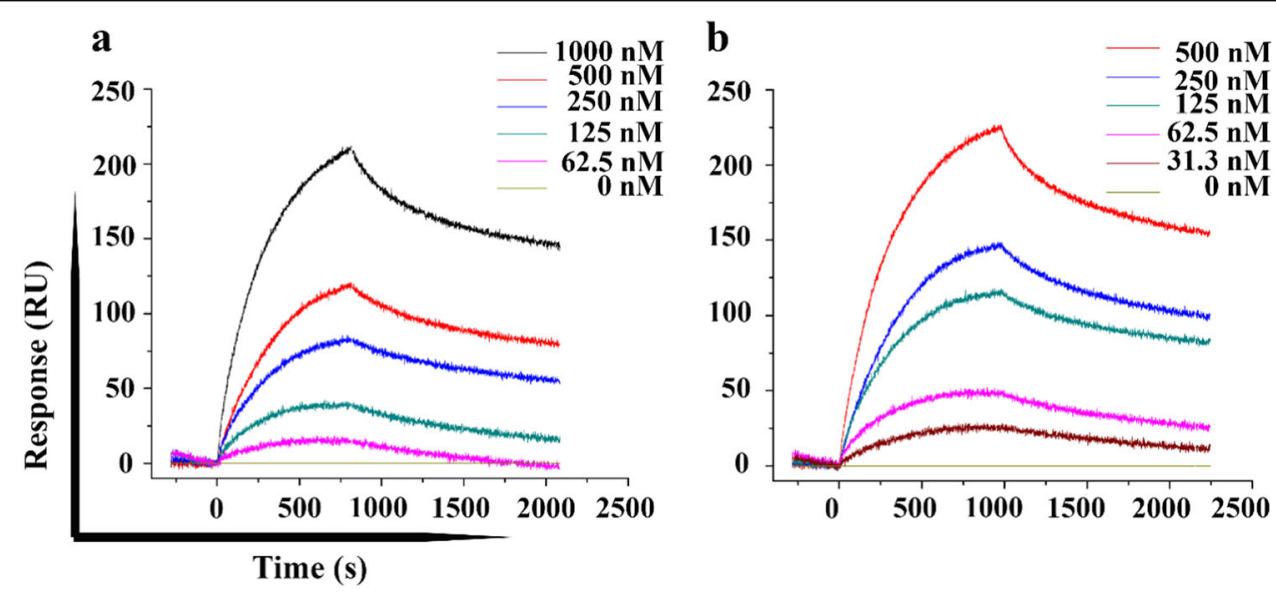

Fig. 7 The locked trimer MIF ${ }^{\mathrm{N} 10 \mathrm{C}}$ binds apo-SOD1 protein with higher affinity than wild type MIF. SPR binding sensograms for the interactions of Apo SOD $1^{\mathrm{WT}}$ with (a) MIF ${ }^{\mathrm{WT}}$ and (b) mutant $\mathrm{MIF}^{\mathrm{N} 110 \mathrm{C}}$. Purified Apo SOD ${ }^{\mathrm{WT}}$ proteins were used as the ligand and recombinant MIF ${ }^{\mathrm{WT}}$ and $\mathrm{MIF}^{\mathrm{N} 110 \mathrm{C}}$ were used as analytes. Concentrations of analytes are mentioned in the image. The sensograms shown are representative of five different experimental sets. The values are statistically valid since chi-square is less than the $10 \%$ of Rmax in the fitted graphs.

SOD1 are more toxic to the cells than non-fibril, disordered aggregates ${ }^{54}$. The change in aggregation pathway may thus explain the ability of MIF to rescue neuronal cells expressing mutant SOD1. Furthermore, the glycine-alanine dipeptide repeats from C9orf72 hexanucleotide expansions, which underlie the most common form of familial ALS, were shown to form toxic amyloid aggregates with a cell-to-cell transmission property $^{61,64,65}$. In support of our current findings, it was shown that mutating the poly(GA) protein changes its aggregation pathway from fibrils to amorphous aggregates, which also suppressed its toxicity ${ }^{64}$.

Recently, Woerner and colleagues have used artificial $\beta$-sheet proteins to show that their cytosolic aggregates affect the nucleocytoplasmic transport of other proteins and RNA. However, the same $\beta$-sheet proteins had no effect when forming aggregates in the nucleus ${ }^{63}$. Based on this evidence that aggregates in the nucleus are less perturbing than their cytosolic counterparts, our results showing that MIF inhibits the sequestration of mutant SOD1 from the nucleus to the cytosol may provide an additional explanation for MIF's protective effect especially considering the fact that nucleocytoplasmic transport defects play a central role in ALS pathogenesis ${ }^{64,66-70}$. Additionally, a study by Zhong et al., proposed that the nuclear clearance of misfolded SOD1 is a protective mechanism of the cell to fight against misfolded SOD1 toxicity in the nucleus ${ }^{27}$. They propose that the misfolding of SOD1 exposes an NES-like sequence, which is normally buried in the correctly folded wild type SOD1, allowing the sequestration of misfolded SOD1 to the cytoplasm ${ }^{27}$. We suggest that MIF's inhibition of the nuclear export of misfolded SOD1 is due to its chaperone activity in the nucleus, preventing the exposure of the NES-like sequence. In this regard, it was recently shown that MIF is recruited to the nucleus by apoptosis-inducing factor (AIF), where it can also function as a nuclease ${ }^{71}$. Thus, whether the alleviation of misfolded SOD1 toxicity results from reducing its accumulation in the nucleus, by inhibiting its export to the cytosol, by modification of its toxic properties (such as aggregation), or by a combination of all-together still needs to be clarified.

In addition, with the recently proposed mechanism for cell-to-cell spreading of misfolded SOD1 as a means of disease propagation ${ }^{72-74}$, it will be important to determine, in future studies, whether MIF may act to limit such spreading considering the potential role of MIF as a chaperone and its extracellular localization under certain conditions.

In conclusion, we propose a novel mechanism for MIF's protective chaperone activity (as described in Fig. 8), independent of its catalytic and signaling functions. The elucidation of the exact mechanism by which MIF suppresses the accumulation of misfolded SOD1, inhibits its association with intracellular membranes, suppresses amyloid aggregation and rescues cells from mutant SOD1 toxicity, requires further investigation. This alternative mechanism proposed in our current research together with an in depth understanding of its essence has the potential to pave the way for the development of therapies for ALS based on MIF and its derivatives.

\section{Materials and methods}

\section{Cell culture and plasmids}

To generate the pcDNA-hMIF, pcDNA-hMIF ${ }^{\mathrm{C} 60 \mathrm{~S}}$, pcDNA-hMIF $^{\mathrm{P} 2 \mathrm{~A}}$, and pcDNA-hMIF ${ }^{\mathrm{N110C}}$ vectors, the 


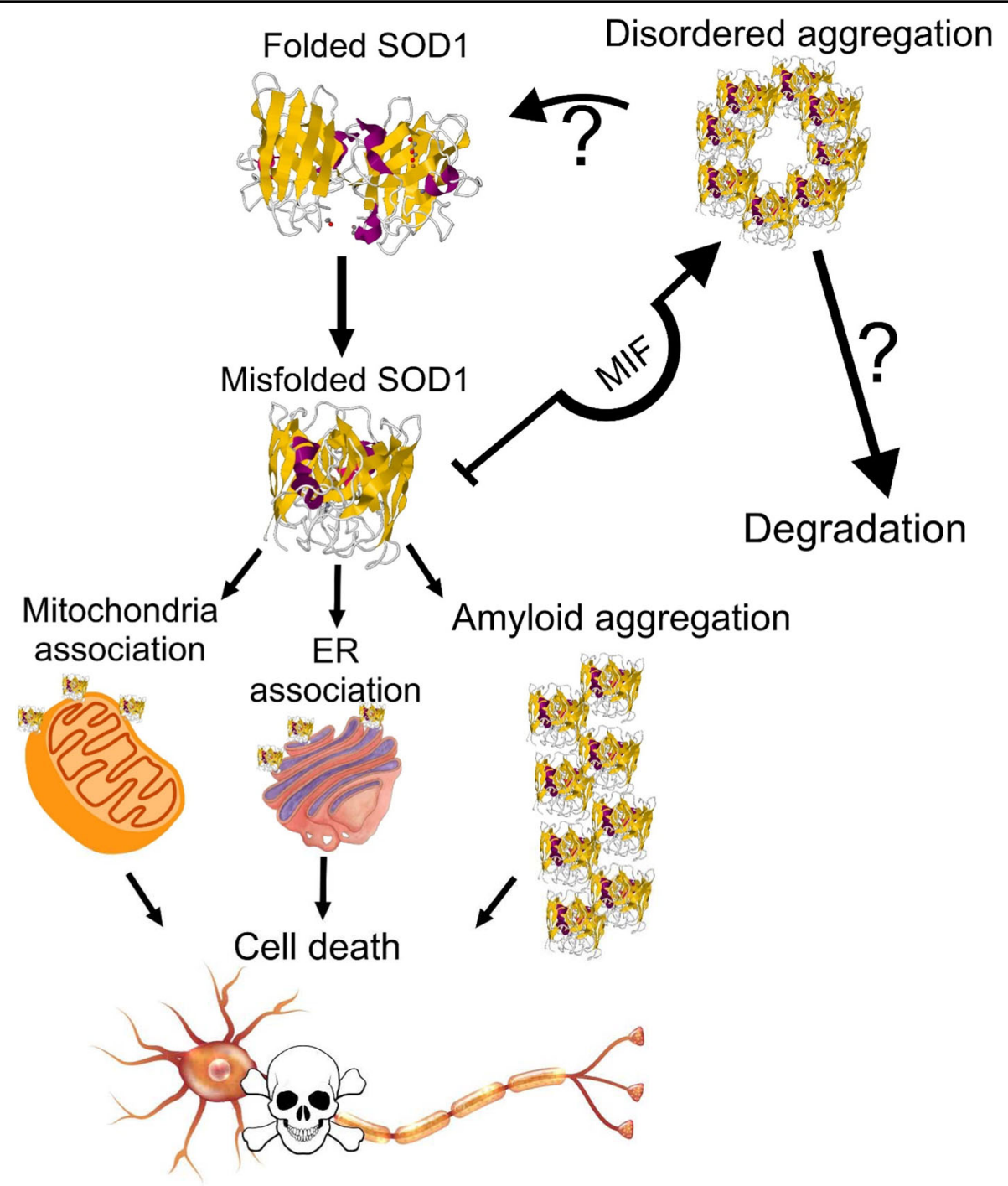

Fig. 8 Proposed model of the chaperone-like activity of MIF. A fraction of mutant SOD1 or wild type SOD1 under stress conditions accumulates as a toxic misfolded protein. This misfolded protein associates with mitochondrial or ER membranes, thereby causing mitochondrial dysfunction or ER stress, respectively, leading to cell death. Alternatively, the misfolded SOD1 proteins may aggregate as toxic amyloid fibrils that cause cell death. By directly interacting with the misfolded SOD1, MIF prevents it from accumulating and associating with intracellular membranes, thereby reducing its toxic effect. In addition, MIF inhibits SOD1 amyloid fibril formation and promotes instead, the formation of less toxic amorphous aggregates.

cDNA of human MIF was amplified by polymerase chain reaction (PCR) and inserted into the pcDNA3.1(-) plasmid using the BamHI and XbaI sites. pCI-hSOD $1^{\text {WT }}$, pCIhSOD $1^{\mathrm{G} 93 \mathrm{~A}}$, and $\mathrm{pCI}-\mathrm{hSOD} 1^{\mathrm{G} 85 \mathrm{R}}$ were generated by inserting human SOD1 constructs into the pCI-NEO vector (Promega), between the EcoRI and the NotI sites.

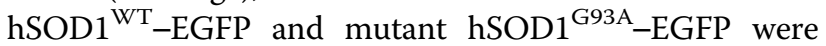
obtained from Jean-Pierre Julien (Laval University, Canada).

NSC-34 cells were grown at $37^{\circ} \mathrm{C}$ and $5 \% \mathrm{CO}_{2}$ in Dulbecco's modified Eagle medium (DMEM) supplemented with $10 \%$ tetracycline-free fetal bovine serum (FBS), L-Glutamine $(2 \mathrm{mM})$, and penicillin $(100 \mathrm{U} / \mathrm{ml})$ / streptomycin $(0.1 \mathrm{mg} / \mathrm{mL})$ (all reagents from Biological Industries). Transfection was performed by using TurboFect (Thermo) according to the manufacturer's protocol. When co-transfections were performed, empty plasmids were transfected as controls. Cell viability was analyzed by using the CellTiter $96 \mathrm{AQ}_{\text {ueous }}$ one-solution cell proliferation assay (Promega) and ELISA at $490 \mathrm{~nm}$, according to the manufacturer's protocol.

\section{Immunoprecipitation}

Whole-cell extracts $(100 \mu \mathrm{g})$ or purified proteins $(4 \mu \mathrm{g})$ were solubilized in immunoprecipitation (IP) buffer [50 $\mathrm{mM}$ Tris- $\mathrm{HCl} \quad(\mathrm{pH}$ 7.4), $150 \mathrm{mM} \quad \mathrm{NaCl}, \quad 1 \mathrm{mM}$ 
ethylenediaminetetraacetic acid (EDTA), $0.5 \%$ Nonidet P40 plus $1 \mathrm{X}$ protease inhibitors] and incubated overnight with $\mathrm{B} 8 \mathrm{H} 10$ or A5C3 (MediMabs) antibodies previously crosslinked to Dynabeads protein G (Invitrogen) with dimethyl pimelimidate (Pierce) according to the manufacturer's instructions. The beads were magnetically isolated and washed three times with IP buffer. Samples were eluted by boiling in a $2 \times$ sample buffer.

\section{Immunoblotting}

Proteins were separated on 13\% SDS-PAGE gel, transferred to nitrocellulose membranes, and probed with various antibodies, including goat anti-SOD1 (C-17; SCB), sheep anti-SOD1 (Calbiochem), monoclonal anti-VDAC/ porin 31HL (Calbiochem), goat anti-MIF (N-18, SCB), rabbit anti-MIF (FL-115, SCB), rabbit anti-human SOD1 (ab52950, Abcam), and rabbit anti-VDAC (ab154856, Abcam). Horseradish peroxidase-conjugated anti-mouse, anti-rabbit, anti-sheep, or anti-goat IgG secondary antibodies (Jackson Immunochemicals) were used and detected by ECL (GE Biosciences).

\section{Protein expression and purification MIF purification}

The pET-IIb plasmid containing human MIF cDNA was used to transform the E. coli BL21 (DE3) expression strain (Real Biotech). Three liters of culture were grown at $37^{\circ} \mathrm{C}$ until the turbidity at $600 \mathrm{~nm}$ reached $0.4-0.6 \mathrm{OD}$. Isopropyl 1-thio-P-D-galactopyranoside (IPTG) was added to obtain a final concentration of $0.5 \mathrm{mM}$ and the incubation continued at $37^{\circ} \mathrm{C}$ overnight. Thereafter, bacteria were harvested by centrifugation (at $4700 \mathrm{xg}$ for $1.5 \mathrm{~h}$ ) and the cell pellet (around $4.5 \mathrm{~g}$ for $600 \mathrm{~mL}$ ) was resuspended to the ratio of $1 \mathrm{~g}: 10 \mathrm{ml}$ of MIF lysis buffer $(20 \mathrm{mM}$ Tris, $20 \mathrm{mM} \mathrm{NaCl}, 0.1 \mathrm{mM}$ PMSF, and PI-complete cocktail tablets, $\mathrm{pH}$ 7.4). The bacteria were lysed by sonication (duration, $6 \mathrm{~min}$; amplitude, $85 \%$; on: $20 \mathrm{~s}$; off: $40 \mathrm{~s}$ ). Bacterial extract was centrifuged at 7000 RCF for $1.5 \mathrm{~h}$. The supernatant was purified through a $0.45 \mu \mathrm{m}$ filter, followed by a $0.22 \mu \mathrm{m}$ filter (syringe-driven filter unit, Millex) and then subjected to Capto $\mathrm{Q} 5 \mathrm{~mL}$ anion exchange chromatography using the AKTA pure chromatography system (GE Healthcare). The Capto Q column was equilibrated with the MIF loading buffer (20 $\mathrm{mM} \mathrm{NaCl}, 20 \mathrm{mM}$ Tris, $\mathrm{pH}$ 7.4, 5 column volumes). The supernatant was loaded onto the column with a flow speed of $1 \mathrm{~mL} / \mathrm{min}$. MIF does not bind to the column under these conditions, and the flow-through fractions containing MIF (Peak UV omission on graph) were collected, combined and left overnight at $4{ }^{\circ} \mathrm{C}$.

The following morning, the solution was centrifuged at 7000 RCF for $1 \mathrm{~h}$, and the supernatant was examined using Capto $\mathrm{S} 5 \mathrm{~mL}$ cation exchange chromatography that had previously been equilibrated with the loading buffer
(5 CV). The supernatant was loaded onto the column in gradual volumes of $7 \mathrm{ml}$ at a flow speed of $0.5 \mathrm{ml} / \mathrm{min}$. The Capto $\mathrm{S}$ column was then washed with the original MIF loading buffer causing weak elution. After the washing, MIF detached from the column as flow through. This loading and eluting procedure of MIF on the Capto S column was repeatedly done in small volumes. The peak fractions were loaded onto a SDS-PAGE gel (13\%). The most purified MIF-containing fractions were combined; centrifuged at $4000 \mathrm{RCF}$ for $20 \mathrm{~min}$ in centrifugal filter units $10 \mathrm{~K}$ (Merck-Millipore), quantified by Bradford assay, aliquoted and stored at $-20^{\circ} \mathrm{C}$.

\section{Purification and evaluation of recombinant SOD ${ }^{\mathrm{WT}}{ }^{\mathrm{T}}$, SOD $1^{\mathrm{G} 93 \mathrm{~A}}$, and $\mathrm{SOD} 1^{\mathrm{G} 85 \mathrm{R}}$ proteins}

Sequences of human $\mathrm{SOD} 1^{\mathrm{WT}}, \mathrm{SOD}^{\mathrm{G} 93 \mathrm{~A}}$, and SOD $1^{\mathrm{G} 85 \mathrm{R}}$ were optimized for codon usage in E. coli, cloned into pHIS1 vector ${ }^{75}$ and expressed as 6His-tagged $(N$-term) soluble proteins in BL21 cells. Cells were grown in $\mathrm{LB}$ medium containing $100 \mu \mathrm{g} / \mathrm{mL}$ ampicillin at $30^{\circ} \mathrm{C}$ for $4 \mathrm{~h}$ and the expression of the recombinant SOD1 proteins was induced by the addition of $0.5 \mathrm{mM}$ IPTG, followed by overnight incubation at $20^{\circ} \mathrm{C}$. Afterwards, bacteria were harvested by centrifugation (at $4700 \times g$ for $1.5 \mathrm{~h}$ ) and the cell pellet (around $8 \mathrm{~g}$ for $600 \mathrm{~mL}$ ) was resuspended in sonication buffer $(50 \mathrm{mM}$ Tris- $\mathrm{HCl}$ pH $7.5,0.5 \mathrm{M} \mathrm{NaCl}$, $2 \mathrm{mM} \beta$-mercaptoethanol, $10 \mathrm{mM}$ imidazole, $1 \mathrm{mg}$ per $1 \mathrm{ml}$ lysozyme, $0.1 \mathrm{mM}$ PMSF and PI- cOmplete cocktail tablets). After $30 \mathrm{~min}$ incubation on ice, the cells were disrupted by sonication (duration, $6 \mathrm{~min}$; amplitude, $85 \%$; on: $20 \mathrm{~s}$; off, $40 \mathrm{~s})$ in a loading buffer $(50 \mathrm{mM}$ $\mathrm{Na}^{+}$/phosphate, $\mathrm{pH} 7.6,0.5 \mathrm{M} \mathrm{NaCl}, 2 \mathrm{mM} \beta$-mercaptoethanol, $10 \mathrm{mM}$ imidazole) containing $1 \mathrm{mg} / \mathrm{mL}$ lysozyme and a protease inhibitor cocktail (Sigma, Israel).

To remove DNA, the crude extract was incubated on ice for $30 \mathrm{~min}$ in the presence of $100 \mathrm{U} / \mathrm{mL}$ bovine pancreas DNasel (Sigma, Israel) and $5 \mathrm{mM} \mathrm{MgSO}_{4}$, followed by 1.5 h centrifugation $(7000 \times g)$ at $4{ }^{\circ} \mathrm{C}$. The supernatant was purified through a $45 \mu \mathrm{m}$ filter, followed by a $22 \mu \mathrm{m}$ filter (syringe-driven filter unit, Millex) and then subjected to a $5 \mathrm{~mL}$ HisTrap FF column (GE Healthcare Life Sciences, Sweden) equilibrated with the loading buffer. The column was washed $(5 \mathrm{CV})$ with a washing buffer $\left(50 \mathrm{mM} \mathrm{Na}^{+}\right.$/ phosphate, $\mathrm{pH} 7.6,0.5 \mathrm{M} \mathrm{NaCl}, 2 \mathrm{mM} \beta$-mercaptoethanol, $20 \mathrm{mM}$ imidazole) and the protein was eluted by a linear 20-400 mM imidazole gradient $(10 \mathrm{CV})$. The peak fractions were dialyzed overnight at $4{ }^{\circ} \mathrm{C}$ against a storage buffer $\left(50 \mathrm{mM} \mathrm{Na}^{+}\right.$/phosphate, $\mathrm{pH} 7.6,0.1 \mathrm{M} \mathrm{NaCl}$, and $10 \%$ glycerol), concentrated by ultrafiltration $(10 \mathrm{kDa}$ cutoff, Millipore, USA), centrifuged at $110,000 \times g$ at $4{ }^{\circ} \mathrm{C}$ for $1 \mathrm{~h}$ using ultracentrifuge (Sorvall M120, Discovery), and stored at $-20^{\circ} \mathrm{C}$ until use. Protein concentration was measured by the Bradford method using bovine serum albumin as the standard. 


\section{ThT aggregation assay for mutant SOD1}

Prior to the aggregation assay, all mixtures containing protein were centrifuged at $10,000 \times g$ at $20^{\circ} \mathrm{C}$ for $10 \mathrm{~min}$ using ultracentrifuge (Sorvall M120, Discovery). SOD1 ${ }^{\text {G93A }}$ or SOD1 ${ }^{\mathrm{G} 85 \mathrm{R}}(50 \mu \mathrm{M})$ with or without MIF $(6.25-50 \mu \mathrm{M})$ were incubated in $200 \mu \mathrm{L}$ of $10 \mathrm{mM} \mathrm{Na}^{+} /$phosphate buffer, $\mathrm{pH} 7.4,150 \mathrm{mM} \mathrm{NaCl}, 5 \mathrm{mM}$ EDTA and $10 \mathrm{mM}$ TCEP in the presence of $20 \mu \mathrm{M}$ Thioflavin T (Sigma Aldrich, Israel) in a black 96-well plate at $37^{\circ} \mathrm{C}$ with fast continuous shaking using a SpectraMax Paradigm (Molecular Devices) ELISA reader. The fluorescence (Ex. $440 \mathrm{~nm}$; Em. $485 \mathrm{~nm}$ ) was measured at $10 \mathrm{~min}$ intervals.

\section{Analysis of SOD1 fibril formation by transmission electron microscopy (TEM)}

Samples for TEM imaging were prepared as described elsewhere $^{76}$. Briefly, at the end of the aggregation assay, $2.5 \mu \mathrm{L}$ samples (diluted 5-fold) were deposited on a carbon-coated copper 300 mesh. After $1 \mathrm{~min}$, the excess liquid was carefully blotted onto filter paper, which was then dried at ambient temperature for $1 \mathrm{~min}$. Uranyl acetate $(5 \mu \mathrm{L}, 2 \%)$ was added to the grid and, after $1 \mathrm{~min}$, the excess of the salt solution was carefully removed with a filter paper. The imaging was performed using a Tecnai G2 12 BioTWIN (FEI) transmission electron microscope with an acceleration voltage of $120 \mathrm{kV}$. Different magnifications were used, depending on the size of the aggregate. The visible features were sensitive to the electron beam exposure, indicating their organic origin.

\section{Surface plasmon resonance}

The binding constants of $\mathrm{MIF}^{\mathrm{WT}}$ and $\mathrm{MIF}^{\mathrm{N} 110 \mathrm{C}}$ mutant with apo-SOD ${ }^{\mathrm{WT}}$ protein, were determined by SPR spectroscopy on a ProteOn XPR36 (Bio-Rad, CA, USA). Poly-histidine tagged apo-SOD1 ${ }^{\mathrm{WT}}$ was immobilized on the surface of the tris-NTA HTG ProteOn chip. $1 \mu \mathrm{g}$ of apo-SOD $1^{\text {WT }}$ was immobilized on the chip in PBST buffer (PBS $300 \mathrm{mM} \mathrm{NaCl}, 0.05 \%$ Tween-20), to give 736 response units (RU). HTB1, Hyperthermophilic protein G B1 domain, $(10 \mu \mathrm{g}, 2068 \mathrm{RU})$ was immobilized on the chip as a negative control. Before each binding assay, the temperature was set at $25{ }^{\circ} \mathrm{C}$. Soluble MIF wild type and MIF mutant (analytes) were then allowed to flow over the surface-bound apo-SOD $1^{\mathrm{WT}}$ separately at a flow rate of $25 \mu \mathrm{l} / \mathrm{min}$. While the analyte was flowing over the surface for $13 \mathrm{~min}$, the interactions of $\mathrm{MIF}^{\mathrm{WT}}$ and $\mathrm{MIF}^{\mathrm{N} 110 \mathrm{C}}$ with apo-SOD $1^{\text {WT }}$ was determined. The next step was to examine the dissociation of the protein, while allowing PBST to flow over the surface for $21 \mathrm{~min}$ at $25 \mu \mathrm{l} / \mathrm{min}$. After each run, a regeneration step was performed with $50 \mathrm{mM} \mathrm{NaOH}$ at a flow rate of $100 \mu \mathrm{L} / \mathrm{min}$. For each protein complex, a sensogram was generated from the RUs measured during the course of the protein-protein interaction subtracting the values of the HTB1 background channel. The dissociation constant $\left(\mathrm{K}_{\mathrm{D}}\right)$ was determined from the sensogram of the equilibriumbinding phase.

\section{Protein crosslinking with glutaraldehyde}

Ten $\mu \mathrm{M}$ (micromolar) of recombinant wild-type or mutant MIF proteins were dissolved in $20 \mathrm{mM}$ sodium phosphate buffer ( $\mathrm{pH}$ 7.2) and incubated for $3 \mathrm{~h}$ in the presence of $1 \%$ glutaraldehyde ${ }^{32}$ at room temperature in constant rotation. The reaction was stopped by adding 25 $\mathrm{mM} \mathrm{NaBH}_{4}$. Samples were then boiled in Laemmli sample buffer without $\beta$-mercapthoethanol and analyzed by $13 \%$ SDS-PAGE followed by immunoblot analysis with antiMIF polyclonal antibody (FL-115).

\section{Statistics}

Values are reported as mean \pm SEM throughout. Student's $t$-tests were used to compare two datasets, after confirming a normal distribution of the data by using the Shapiro-Wilk normality test. A one-way ANOVA with Tukey's posthoc analysis was used to analyze the nucleus/ cytoplasm SOD1 distribution. Significance was set at a confidence level of 0.05 .

\section{Acknowledgements}

We thank all members of the A.I. laboratory for their helpful comments and suggestions, and Liat Tsoran for her technical help. This work was supported by grants from the Israel Science Foundation (ISF \#124/14), the United States-Israel Binational Science Foundation (BSF \#2013325), the FP7 Marie Curie Career Integration Grant (CIG \# 333794), the German-Israeli Foundation for Scientific Research and Development (GIF \# I-2320-1089.13), and the National Institute for Psychobiology in Israel (NIPI \#b133-14/15).

\section{Author details}

'Department of Physiology and Cell Biology, Faculty of Health Sciences, BenGurion University of the Negev, P.O.B. 653, Beer Sheva 84105, Israel.

${ }^{2}$ Department of Biotechnology Engineering, Faculty of Engineering, BenGurion University of the Negev, P.O.B. 653, Beer Sheva 84105, Israel. ${ }^{3}$ The National Institute for Biotechnology in the Negev, P.O.B. 653, Beer Sheva 84105 , Israel. ${ }^{4}$ Department of Clinical Biochemistry and Pharmacology, Faculty of Health Sciences, Ben-Gurion University of the Negev, P.O.B. 653, Beer Sheva 84105, Israel. Institute for Stroke and Dementia Research (ISD), LudwigMaximilians University, D-81377 Munich, Germany. ${ }^{6}$ The Zlotowski Center for Neuroscience, Ben-Gurion University of the Negev, P.O.B. 653, Beer Sheva 84105 , Israel

\section{Conflict of interest}

The authors declare that they have no conflict of interest.

\section{Publisher's note}

Springer Nature remains neutral with regard to jurisdictional claims in published maps and institutional affiliations.

\section{Supplementary information}

The online version of this article https://doi.org/10.1038/s41419-017-0130-4 contains supplementary material.

Received: 3 October 2017 Revised: 1 November 2017 Accepted: 7 November 2017

Published online: 25 January 2018 


\section{References}

1. Da Cruz, S. \& Cleveland, D. W. Understanding the role of TDP-43 and FUS/TLS in ALS and beyond. Curr. Opin. Neurobiol. 21, 904-919 (2011).

2. Rosen, D. R. et al. Mutations in $\mathrm{Cu} / \mathrm{Zn}$ superoxide dismutase gene are associated with familial amyotrophic lateral sclerosis. Nature 362, 59-62 (1993).

3. Battistini, S. et al. SOD1 mutations in amyotrophic lateral sclerosis. J. Neurol. 252, 782-788 (2005)

4. Al-Chalabi, A. \& Leigh, P. N. Recent advances in amyotrophic lateral sclerosis. Curr. Opin. Neurol. 13, 397-405 (2000).

5. Bruijn, L. I., Miller, T. M. \& Cleveland, D. W. Unraveling the mechanisms involved in motor neuron degeneration in ALS. Annu. Rev. Neurosci. 27, 723-749 (2004).

6. Abu-Hamad, S., Kahn, J., Leyton-Jaimes, M. F., Rosenblatt, J. \& Israelson, A. Misfolded SOD1 accumulation and mitochondrial association contribute to the selective vulnerability of motor neurons in familial ALS: correlation to human disease. ACS Chem. Neurosci. 8, 2225-2234 (2017).

7. Prudencio, M., Hart, P. J., Borchelt, D. R. \& Andersen, P. M. Variation in aggregation propensities among ALS-associated variants of SOD1: correlation to human disease. Hum. Mol. Genet. 18, 3217-3226 (2009).

8. Wang, Q., Johnson, J. L., Agar, N. Y. \& Agar, J. N. Protein aggregation and protein instability govern familial amyotrophic lateral sclerosis patient survival. PLOS Biol. 6, e170 (2008)

9. Banerjee, $V$. et al. Superoxide dismutase 1 (SOD1)-derived peptide inhibits amyloid aggregation of familial amyotrophic lateral sclerosis SOD1 mutants. ACS Chem. Neurosci. 7, 1595-1606 (2016).

10. Forsberg, $\mathrm{K}$. et al. Novel antibodies reveal inclusions containing non-native SOD1 in sporadic ALS patients. PLoS ONE 5, e11552 (2010).

11. Ohi, T., Nabeshima, K., Kato, S., Yazawa, S. \& Takechi, S. Familial amyotrophic lateral sclerosis with His46Arg mutation in $\mathrm{Cu} / \mathrm{Zn}$ superoxide dismutase presenting characteristic clinical features and Lewy body-like hyaline inclusions. J. Neurol. Sci. 225, 19-25 (2004).

12. Deng, $\mathrm{H}$. X. et al. Conversion to the amyotrophic lateral sclerosis phenotype is associated with intermolecular linked insoluble aggregates of SOD1 in mitochondria. Proc. Natl. Acad. Sci. USA. 103, $7142-7147$ (2006).

13. Israelson, A. et al. Misfolded mutant SOD1 directly inhibits VDAC1 conductance in a mouse model of inherited ALS. Neuron 67, 575-587 (2010).

14. Liu, J. et al. Toxicity of familial ALS-linked SOD1 mutants from selective recruitment to spinal mitochondria. Neuron 43, 5-17 (2004)

15. Mattiazzi, M. et al. Mutated human SOD1 causes dysfunction of oxidative phosphorylation in mitochondria of transgenic mice. J. Biol. Chem. 277, 29626-29633 (2002)

16. Vande Velde, C., Miller, T. M., Cashman, N. R. \& Cleveland, D. W. Selective association of misfolded ALS-linked mutant SOD1 with the cytoplasmic face of mitochondria. Proc. Natl. Acad. Sci. USA. 105, 4022-4027 (2008).

17. Vijayvergiya, C., Beal, M. F., Buck, J. \& Manfredi, G. Mutant superoxide dismutase 1 forms aggregates in the brain mitochondrial matrix of amyotrophic lateral sclerosis mice. J. Neurosci. 25, 2463-2470 (2005).

18. Mori, A. et al. Derlin-1 overexpression ameliorates mutant SOD1-induced endoplasmic reticulum stress by reducing mutant SOD1 accumulation. Neurochem. Int. 58, 344-353 (2011).

19. Homma, K. et al. SOD1 as a molecular switch for initiating the homeostatic ER stress response under zinc deficiency. Mol. Cell. 52, 75-86 (2013).

20. Fujisawa, $\mathrm{T}$. et al. A novel monoclonal antibody reveals a conformational alteration shared by amyotrophic lateral sclerosis-linked SOD1 mutants. Ann. Neurol. 72, 739-749 (2012).

21. Nishitoh, $\mathrm{H}$. et al. ALS-linked mutant SOD1 induces ER stress- and ASK1dependent motor neuron death by targeting Derlin-1. Genes Dev. 22, 1451-1464 (2008)

22. Li, Q. et al. ALS-linked mutant superoxide dismutase 1 (SOD1) alters mitochondrial protein composition and decreases protein import. Proc. Natl. Acad. Sci. USA. 107, 21146-21151 (2010).

23. Pedrini, S. et al. ALS-linked mutant SOD1 damages mitochondria by promoting conformational changes in BCl-2. Hum. Mol. Genet. 19, 2974-2986 (2010).

24. Israelson, A. et al. Macrophage migration inhibitory factor as a chaperone inhibiting accumulation of misfolded SOD1. Neuron 86, 218-232 (2015).

25. Leyton-Jaimes, M. F. et al. Endogenous macrophage migration inhibiton factor reduces the accumulation and toxicity of misfolded SOD1 in a mouse model of ALS. PNAS 113, 10198-10203 (2016).

26. Crapo, J. D., Oury, T., Rabouille, C., Slot, J. W. \& Chang, L. Y. Copper, zinc superoxide dismutase is primarily a cytosolic protein in human cells. Proc. Natl. Acad. Sci. USA. 89, 10405-10409 (1992).
27. Zhong $Y$. et al. Nuclear export of misfolded SOD1 mediated by a normally buried NES-like sequence reduces proteotoxicity in the nucleus. Elife 6, (2017). CITE AS: eLife 2017;6:e23759

28. Sun, H. W., Bernhagen, J., Bucala, R. \& Lolis, E. Crystal structure at 2.6-A resolution of human macrophage migration inhibitory factor. Proc. Natl. Acad. Sci. USA. 93, 5191-5196 (1996).

29. Lubetsky, J. B., Swope, M., Dealwis, C., Blake, P. \& Lolis, E. Pro-1 of macrophage migration inhibitory factor functions as a catalytic base in the phenylpyruvate tautomerase activity. Biochemistry 38, 7346-7354 (1999).

30. Kleemann, R. et al. Disulfide analysis reveals a role for macrophage migration inhibitory factor (MIF) as thiol-protein oxidoreductase. J. Mol. Biol. 280, 85-102 (1998).

31. Fan, C. et al. MIF intersubunit disulfide mutant antagonist supports activation of CD74 by endogenous MIF trimer at physiologic concentrations. Proc. Natl. Acad. Sci. USA. 110, 10994-10999 (2013).

32. Mischke, R., Kleemann, R., Brunner, H. \& Bernhagen, J. Cross-linking and mutational analysis of the oligomerization state of the cytokine macrophage migration inhibitory factor (MIF). FEBS Lett. 427, 85-90 (1998).

33. Ouertatani-Sakouhi, $H$. et al. Identification and characterization of novel classes of macrophage migration inhibitory factor (MIF) inhibitors with distinct mechanisms of action. J. Biol. Chem. 285, 26581-26598 (2010).

34. Grad, L. I. et al. Intercellular propagated misfolding of wild-type Cu/Zn superoxide dismutase occurs via exosome-dependent and -independent mechanisms. Proc. Natl. Acad. Sci. USA. 111, 3620-3625 (2014).

35. Bosco, D. A. et al. Wild-type and mutant SOD1 share an aberrant conformation and a common pathogenic pathway in ALS. Nat. Neurosci. 13, 1396-1403 (2010).

36. Forsberg, K., Andersen, P. M., Marklund, S. L. \& Brannstrom, T. Glia nuclear aggregates of superoxide dismutase-1 are regularly present in patients with amyotrophic lateral sclerosis. Acta Neuropathol. 121, 623-634 (2011).

37. Guareschi, S. et al. An over-oxidized form of superoxide dismutase found in sporadic amyotrophic lateral sclerosis with bulbar onset shares a toxic mechanism with mutant SOD1. Proc. Natl. Acad. Sci. USA. 109, 5074-5079 (2012).

38. Kabashi, E., Valdmanis, P. N., Dion, P. \& Rouleau, G. A. Oxidized/misfolded superoxide dismutase-1: the cause of all amyotrophic lateral sclerosis? Ann. Neurol. 62, 553-559 (2007)

39. Pokrishevsky, E. et al. Aberrant localization of FUS and TDP43 is associated with misfolding of SOD1 in amyotrophic lateral sclerosis. PLOS ONE 7, e35050 (2012).

40. Zetterstrom, P. Andersen, P. M., Brannstrom, T. \& Marklund, S. L. Misfolded superoxide dismutase-1 in CSF from amyotrophic lateral sclerosis patients. J. Neurochem. 117, 91-99 (2011).

41. Ayers, J. I. et al. Distinct conformers of transmissible misfolded SOD1 distinguish human SOD1-FALS from other forms of familial and sporadic ALS. Acta Neuropathol. 132, 827-840 (2016).

42. Ayers, J. I. et al. Conformational specificity of the C4F6 SOD1 antibody; low frequency of reactivity in sporadic ALS cases. Acta Neuropathol. Commun. 2, 55 (2014).

43. Brotherton, T. E. et al. Localization of a toxic form of superoxide dismutase 1 protein to pathologically affected tissues in familial ALS. Proc. Natl. Acad. Sci. USA. 109, 5505-5510 (2012).

44. Da Cruz S. et al. Misfolded SOD1 is not a primary component of sporadic ALS. Acta. Neuropathol. 134(1):97-111 (2017).

45. Kerman, A. et al. Amyotrophic lateral sclerosis is a non-amyloid disease in which extensive misfolding of SOD1 is unique to the familial form. Acta Neuropathol. 119, 335-344 (2010).

46. Liu, H. N. et al. Lack of evidence of monomer/misfolded superoxide dismutase-1 in sporadic amyotrophic lateral sclerosis. Ann. Neurol. 66, 75-80 (2009).

47. Leyton-Jaimes M. F., Kahn J., Israelson A. Macrophage migration inhibitory factor: a multifaceted cytokine implicated in multiple neurological diseases. Exp Neurol. (in press).

48. George, M. \& Vaughan, J. H. In vitro cell migration as a model for delayed hypersensitivity. Proc. Soc. Exp. Biol. Med. 111, 514-521 (1962).

49. Cherepkova, O. A., Lyutova, E. M., Eronina, T. B. \& Gurvits, B. Y. Chaperone-like activity of macrophage migration inhibitory factor. Int. J. Biochem. Cell. Biol. 38, 43-55 (2006). 
50. Cherepkova, O. A., Lutova, E. M. \& Gurvits, B. Y. Charge heterogeneity of bovine brain macrophage migration inhibitory factor. Neurochem. Res. 30, 151-158 (2005).

51. El-Turk, F. et al. The conformational flexibility of the carboxy terminal residues $105-114$ is a key modulator of the catalytic activity and stability of macrophage migration inhibitory factor. Biochemistry 47, 10740-10756 (2008).

52. Reidy, T. et al. Homotrimeric macrophage migration inhibitory factor (MIF) drives inflammatory responses in the corneal epithelium by promoting caveolin-rich platform assembly in response to infection. J. Biol. Chem. $\mathbf{2 8 8}$ 8269-8278 (2013)

53. Sun, H. W. et al. The subunit structure of human macrophage migration inhibitory factor: evidence for a trimer. Protein Eng. 9, 631-635 (1996).

54. Bhatia, N. K. et al. Curcumin binds to the pre-fibrillar aggregates of $\mathrm{Cu} / \mathrm{Zn}$ superoxide dismutase (SOD1) and alters its amyloidogenic pathway resulting in reduced cytotoxicity. Biochim. Biophys. Acta 1854, 426-436 (2015).

55. Chattopadhyay, M. et al. Initiation and elongation in fibrillation of ALS-linked superoxide dismutase. Proc. Natl. Acad. Sci. USA. 105, 18663-18668 (2008).

56. Ida, M. et al. Structural basis of $\mathrm{Cu}, \mathrm{Zn}$-superoxide dismutase amyloid fibri formation involves interaction of multiple peptide core regions. J. Biochem. 159, 247-260 (2016)

57. Ivanova, M. I. et al. Aggregation-triggering segments of SOD1 fibril formation support a common pathway for familial and sporadic ALS. Proc. Natl. Acad. Sci. USA. 111, 197-201 (2014).

58. Leal, S. S., Cardoso, I., Valentine, J. S. \& Gomes, C. M. Calcium ions promote superoxide dismutase 1 (SOD1) aggregation into non-fibrillar amyloid: a link to toxic effects of calcium overload in amyotrophic lateral sclerosis (ALS)? J. Biol. Chem. 288, 25219-25228 (2013).

59. Leal, S. S., Cristovao, J. S., Biesemeier, A., Cardoso, I. \& Gomes, C. M. Aberrant zinc binding to immature conformers of metal-free copper-zinc superoxide dismutase triggers amorphous aggregation. Metallomics 7, 333-346 (2015).

60. Roberts, $\mathrm{K}$. et al. Extracellular aggregated $\mathrm{Cu} / \mathrm{Zn}$ superoxide dismutase activates microglia to give a cytotoxic phenotype. Glia 61, 409-419 (2013).

61. Chang, Y. J., Jeng, U. S., Chiang, Y. L., Hwang, I. S. \& Chen, Y. R. The glycine-alanine dipeptide repeat from C9orf72 hexanucleotide expansions forms toxic amyloids possessing cell-to-cell transmission properties. J. Biol. Chem. 291, 4903-4911 (2016).

62. Liu, C. et al. Out-of-register beta-sheets suggest a pathway to toxic amyloid aggregates. Proc. Natl. Acad. Sci. USA. 109, 20913-20918 (2012).
63. Woerner, A. C. et al. Cytoplasmic protein aggregates interfere with nucleocytoplasmic transport of protein and RNA. Science 351, 173-176 (2016).

64. Zhang, Y. J. et al. C9ORF72 poly(GA) aggregates sequester and impair HR23 and nucleocytoplasmic transport proteins. Nat. Neurosci. 19, 668-677 (2016).

65. Flores, B. N. et al. Distinct C9orf72-associated dipeptide repeat structures correlate with neuronal toxicity. PLOS ONE 11, e0165084 (2016).

66. Freibaum, B. D. et al. GGGGCC repeat expansion in C9orf72 compromises nucleocytoplasmic transport. Nature 525, 129-133 (2015).

67. Jovicic, A. et al. Modifiers of C9orf72 dipeptide repeat toxicity connec nucleocytoplasmic transport defects to FID/ALS. Nat. Neurosci. 18, 1226-1229 (2015).

68. Shani T., Levy M., Israelson A. Assay to measure nucleocytoplasmic transport in real time within motor neuron-like NSC-34 cells. J Vis Exp. (2017). CITE AS: JoVE 123: e55676 (2017)

69. Shi, K. Y. et al. Toxic PRn poly-dipeptides encoded by the C9orf72 repeat expansion block nuclear import and export. Proc. Natl. Acad. Sci. USA. 114, E1111-E1117 (2017).

70. Zhang, K. et al. The C9orf72 repeat expansion disrupts nucleocytoplasmic transport. Nature 525, 56-61 (2015)

71. Wang $Y$. et al. A nuclease that mediates cell death induced by DNA damage and poly(ADP-ribose) polymerase-1. Science 354, (2016). Science 354(6308) in press (2016)

72. Grad, L. I. \& Cashman, N. R. Prion-like activity of Cu/Zn superoxide dismutase: implications for amyotrophic lateral sclerosis. Prion 8, 33-41 (2014).

73. Grad, L. I. et al. Intermolecular transmission of superoxide dismutase 1 misfolding in living cells. Proc. Natl. Acad. Sci. USA. 108, 16398-16403 (2011).

74. Munch, C., O'Brien, J. \& Bertolotti, A. Prion-like propagation of mutant superoxide dismutase-1 misfolding in neuronal cells. Proc. Natl. Acad. Sci. USA 108 3548-3553 (2011).

75. Sheffield, P., Garrard, S. \& Derewenda, Z. Overcoming expression and purification problems of RhoGDI using a family of "parallel" expression vectors. Protein Expr. Purif. 15, 34-39 (1999).

76. Banerjee, V. \& Das, K. P. Modulation of pathway of insulin fibrillation by a small molecule helix inducer 2,2,2-trifluoroethanol. Colloid Surf. B Biointerfaces 92 142-150 (2012). 